\title{
Study on Preparation of Porous Ceramics by Using Industrial Wastes
}

\author{
Zhihua Xu \\ School of Art Design, Jingdezhen Ceramic Institute, China
}

\begin{abstract}
Coal gangue is a kind of industrial waste bring in the production of coal and the stock pile is very large in China. These coal gangue dumps not only caused environmental pollution but also caused by the waste of resources. This paper studied on the preparation of porous ceramics by using coal gangue from the Huainan area. In the process of research, the effect of the content of pore forming agent, sintering temperature, heat-retaining time and acid leaching conditions on porosity and compressive strength of porous ceramics were investigated respectively. Finally find out the optimum route, the porous ceramic with high apparent porosity and high compressive strength were prepared. This study can not only bring huge environmental benefits but also can bring certain economic benefits, and has important significance of coal gangue reuse.

KEYWORD: industrial waste; porous ceramics; coal gangue; preparation.
\end{abstract}

\section{BACKGROUND}

In China, coal accounted for about $75 \%$ of the entire energy reserves, is an important pillar of the energy. Coal gangue is the solid waste produced in the process of coal mining, which accounts for about $18 \%$ of the total coal production (Wang Xianzheng, 2014). According to official statistics, China's accumulation of stockpiling of coal gangue about 45 million tons and coal gangue new annual production of about 3.5 million tons of, and comprehensive recovery rate of less than 20\% (Yang Yue, 2014). The storage form of coal gangue is usually piled up in the open air, and this will lead to a series of environmental problems. For example, coal gangue in the role of weathering and rain, will release a lot of heavy metal ions, pollution near the soil and groundwater, and thus affect the health of nearby residents (Qin Jianliang, 2015).

With the development of science and technology, people on coal gangue understanding deepening, coal gangue was no longer regarded as a kind of solid waste, but as a resource is widely used in many fields, such as chemical industry, building materials, light industry and so on. Through of coal gangue chemical composition analysis showed that, the main component is $\mathrm{SiO}_{2}$ and $\mathrm{Al}_{2} \mathrm{O}_{3}$, and production of ceramic raw materials similar. In addition to coal gangue it also has large number of micro pores and high specific surface area, so using coal gangue as main raw materials for the preparation of porous ce- ramics has become an important direction of the coal gangue applied research (Qi Fei et al, 2015). In this paper, the influence of different process conditions on the preparation of porous ceramics was studied, and the optimum technological process was determined.

\section{EXPERIMENTAL RAW MATERIALS}

In this paper, porous ceramics were prepared by adding pore forming agent, the use of raw materials in addition to coal gangue, as well as pore forming agent, dispersing agent and mullite fiber. The coal gangue is taken from the Huainan area, the pore forming agent is starch, and the dispersing agent is sodium hydroxide. The chemical composition of coal gangue is shown in Table 1.

Table 1 The chemical composition of coal gangue

\begin{tabular}{llllllll}
\hline $\begin{array}{l}\text { Chemical } \\
\text { composition }\end{array}$ & $\mathrm{SiO}_{2}$ & $\mathrm{Al}_{2} \mathrm{O}_{3}$ & $\mathrm{Fe}_{2} \mathrm{O}_{3}$ & $\mathrm{CaO}$ & $\mathrm{MgO}$ & $\mathrm{SO}_{3}$ & loss \\
\hline Content (\%) & 43.86 & 14.43 & 5.48 & 8.92 & 0.54 & 0.78 & 25.99 \\
\hline
\end{tabular}

Under normal circumstances, the coal gangue is massive, so coal gangue must be pretreated before in the preparation of porous ceramics. Including crushing, ball milling, sieving, acid leaching and other processes. This is to remove impurities from coal gangue and to improve the efficiency of the reaction. 
In Figure 1, the process of removing impurities from coal gangue by acid leaching is indicated.

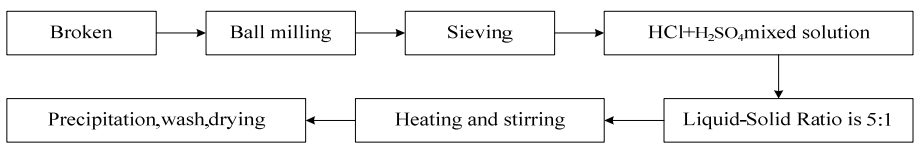

Figure 1 Process of removing impurities from coal gangue by acid leaching is indicated

\section{EXPERIMENTAL PROCEDURE AND RESULTS REPRESENTATION}

Figure 2 represent the process of preparation of porous ceramics by adding pore forming agent.

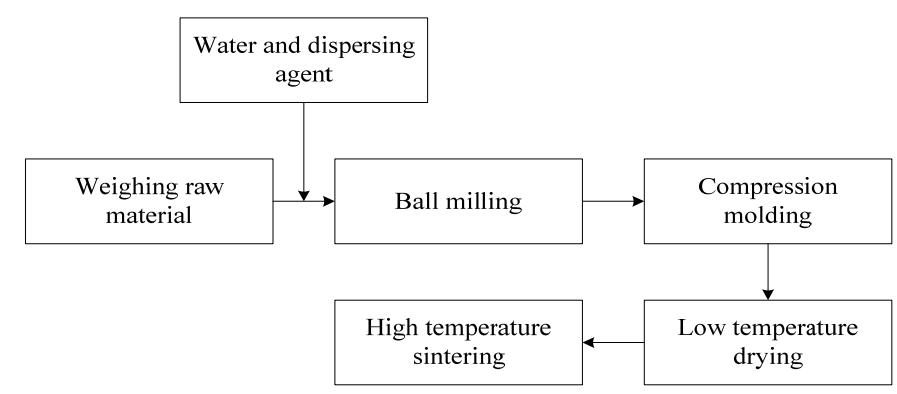

Figure 2 Process flow of porous ceramics prepared by adding pore forming agent

After the samples were made, need to measure the parameters of the sample. The apparent porosity and compressive strength are the two most important indicators of the porous ceramics (Zhang Zhihao et al, 2015). The two indexes of the samples are measured by the following methods:

\subsection{Archimedes boiling method}

Archimedes boiling method is used to measure the apparent porosity of the samples, the method of reference to the national standard GBTI966-1996. The formula for calculating the apparent porosity is as follows:

$$
\mathrm{P}_{\mathrm{a}}=\frac{\mathrm{Mr}_{8}-\mathrm{MI}_{1}}{\mathrm{~F}}
$$

In this formula, $\mathrm{P}_{\mathrm{a}}$-apparent porosity (\%);

M1-quality of dried sample (kg);

$\mathrm{M}_{2}$ - Quality of saturated samples (kg);

$\mathrm{V}$ - Volume of water discharged from the sample $\left(\mathrm{mm}^{3}\right)$.

\subsection{Compressive strength}

The compressive strength of the sample is determined by reference to the national standard
GB1964-1980, and the formula for calculating the compressive strength is as follows:

$$
\mathrm{R}_{s}=\frac{\mathrm{P}}{8}
$$

In this formula, $\mathrm{R}_{\mathrm{c}^{-}}$compressive strength (Mpa);

P- failure load(N);

S- Force area of sample $\left(\mathrm{mm}^{2}\right)$.

\section{RESULT ANALYSIS}

\subsection{Effect of pore forming agent content on apparent porosity and compressive strength of porous ceramics}

The effect of pore forming agent content on the porosity and strength of porous ceramics was investigated in this experiment. In this experiment, the variable is content of pore forming agent, respectively $40 \%, 50 \%, 60 \%$ and $70 \%$. Other conditions as shown in table 2.

Table 2 Specific experimental conditions

\begin{tabular}{ll}
\hline & Specific conditions \\
\hline $\begin{array}{l}\text { Sintering } \\
\text { temperature }\end{array}$ & $1200^{\circ} \mathrm{C}$ \\
$\begin{array}{l}\text { Heat-retaining } \\
\text { time }\end{array}$ & $2 \mathrm{~h}$ \\
$\begin{array}{l}\text { Dispersant } \\
\text { content }\end{array}$ & $0.1 \%$ \\
$\begin{array}{l}\text { Acid leaching } \\
\text { condition }\end{array}$ & $\begin{array}{l}3 \% \mathrm{HCl}+16 \% \mathrm{H}_{2} \mathrm{SO}_{4}, \text { liquid to solid ratio is } \\
5: 1, \text { heating and stirring in } 90^{\circ} \mathrm{C} \text { for } 4 \mathrm{~h}\end{array}$ \\
\hline
\end{tabular}

Effect of pore forming agent content on porosity and compressive strength of porous ceramics as shown in Figure 3.

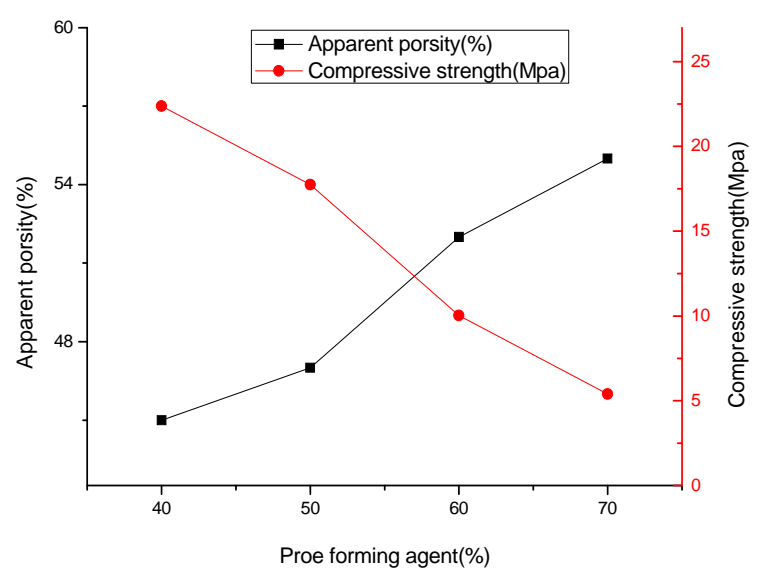

Figure 3 The effect of pore forming agent content on the porosity and strength of porous ceramics

It can be seen from Figure 3, with the increase of the content of pore forming agent, the porosity increased, compressive strength decreased continuously. Adding pore forming agent preparing porous ceramic is the basic principle of pore volume in the 
body to occupy a certain internal, the pore forming agent left burning pore formation of porous structure after high temperature sintering. When the content of pore forming agents increased from $40 \%$ to $50 \%$, significant changes in porosity and compressive strength is not obvious. This is because there are some gaps in the aggregate, when the amount of pore forming agent did not reach fills the gap between the aggregate, the content of pore forming agent has little effect on the porosity and the compressive strength of porous ceramics (Gong Lunlun et al, 2015). But with the increase of content of pore forming agent, the accumulation state of material particles is changed and the inter granular pores become larger. Comprehensive consideration, when adding pore forming agent content is $60 \%$, the porous ceramics can obtain high compressive strength and high apparent porosity.

\subsection{Effect of sintering temperature on apparent porosity and compressive strength of porous ceramic}

In this experiment, the sintering temperature is variable, respectively $1150{ }^{\circ} \mathrm{C}, 1200{ }^{\circ} \mathrm{C}, 1250{ }^{\circ} \mathrm{C}$ and $1300^{\circ} \mathrm{C}$. Other conditions as shown in table 3 .

Table 3 Specific experimental conditions

\begin{tabular}{ll}
\hline & Specific conditions \\
\hline $\begin{array}{l}\text { pore forming } \\
\text { agent content }\end{array}$ & $60 \%$ \\
$\begin{array}{l}\text { Heat-retaining } \\
\text { time }\end{array}$ & $2 \mathrm{~h}$ \\
$\begin{array}{l}\text { Dispersant } \\
\text { content }\end{array}$ & $0.1 \%$ \\
$\begin{array}{l}\text { Acid leaching } \\
\text { condition }\end{array}$ & $3 \% \mathrm{HCl}+16 \% \mathrm{H}_{2} \mathrm{SO}_{4}$, liquid to solid ratio is \\
\hline
\end{tabular}

Effect of sintering temperature on porosity and compressive strength of porous ceramics as shown in Figure 4.

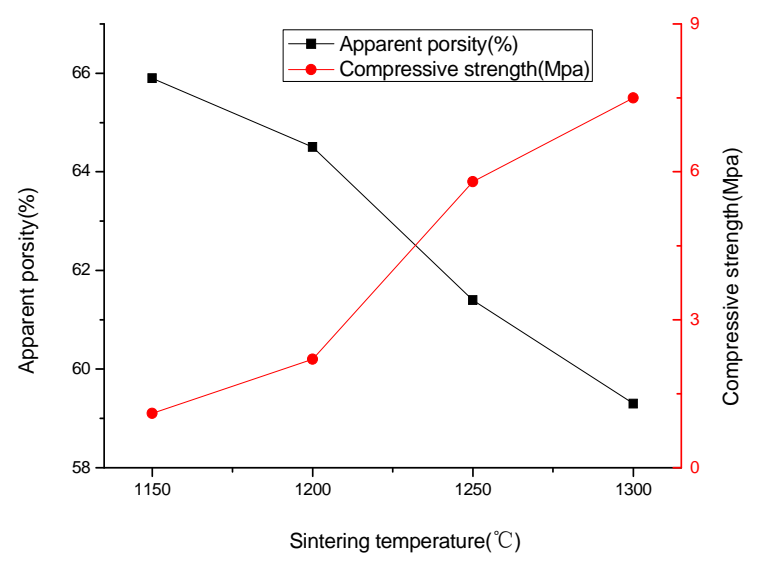

Figure 4 The effect of sintering temperature on porosity and compressive strength of porous ceramics

Figure 4 shows that with an increase in sintering temperature, the porosity decreased, the compressive strength increased. This is because the increase of sintering temperature bring that the liquid phase increases between the particles, leads to reduce the apparent porosity and increase the compressive strength. Comprehensive consideration, the sintering temperature is $1250^{\circ} \mathrm{C}$ centigrade is the best choice.

\subsection{Effect of heat-retaining time on apparent porosity and compressive strength of porous ceramic}

In this experiment, the heat-retaining time is variable, respectively $2 \mathrm{~h}, 3 \mathrm{~h}, 4 \mathrm{~h}, 5 \mathrm{~h}$ and $6 \mathrm{~h}$. Other conditions as shown in table 4.

Table 4 Specific experimental conditions

\begin{tabular}{ll}
\hline \multicolumn{2}{l}{ Specific conditions } \\
\hline $\begin{array}{l}\text { pore forming } \\
\text { Sintering }\end{array}$ & $60 \%$ \\
$\begin{array}{l}\text { temperature } \\
\text { Dispersant }\end{array}$ & $1250^{\circ} \mathrm{C}$ \\
content & $0.1 \%$ \\
$\begin{array}{l}\text { Acid leaching } \\
\text { condition }\end{array}$ & $3 \% \mathrm{HCl}+16 \% \mathrm{H}_{2} \mathrm{SO}_{4}$, liquid to solid ratio is \\
\hline
\end{tabular}

Effect of heat-retaining time on porosity and compressive strength of porous ceramics as shown in Figure 5.

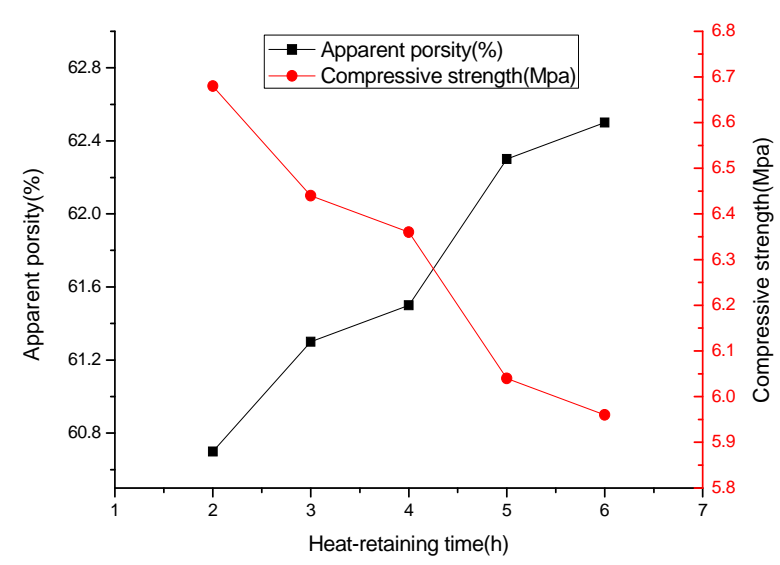

Figure 5 The effect of heat-retaining time on porosity and compressive strength of porous ceramics

It can be seen from Figure 5, with the increase of the holding time, the compressive strength increased, the porosity decreased. This is because with the prolongation of heat-retaining time, the sintering degree increased, the body continues to shrink, densification. So we can keep the temperature for 2 hours. 


\subsection{Effect of acid concentration on apparent porosity and compressive strength of porous ceramic}

In this experiment, the acid concentration is variable, respectively $3 \% \mathrm{HCl}+16 \% \mathrm{H}_{2} \mathrm{SO}_{4}$, $5 \% \mathrm{HCl}+21 \% \mathrm{H}_{2} \mathrm{SO}_{4}$ and $7 \% \mathrm{HCl}+26 \% \mathrm{H}_{2} \mathrm{SO}_{4}$. h, 3h, $4 \mathrm{~h}, 5 \mathrm{~h}$ and $6 \mathrm{~h}$. Other conditions as shown in table 5.

Table 5 Specific experimental conditions

\begin{tabular}{ll}
\hline & Specific conditions \\
\hline $\begin{array}{l}\text { pore forming } \\
\text { agent content }\end{array}$ & $60 \%$ \\
$\begin{array}{l}\text { Sintering } \\
\text { temperature }\end{array}$ & $1250^{\circ} \mathrm{C}$ \\
$\begin{array}{l}\text { Heat-retaining } \\
\text { time }\end{array}$ & $2 \mathrm{~h}$ \\
$\begin{array}{l}\text { Dispersant } \\
\text { content }\end{array}$ & $0.1 \%$ \\
$\begin{array}{l}\text { Acid leaching } \\
\text { condition }\end{array}$ & $\begin{array}{l}\text { liquid to solid ratio is } 5: 1 \text {, heating and stir- } \\
\text { ring in } 90^{\circ} \mathrm{C} \text { for } 4 \mathrm{~h}\end{array}$ \\
\hline
\end{tabular}

Effect of acid concentration on porosity and compressive strength of porous ceramics as shown in Figure 6.

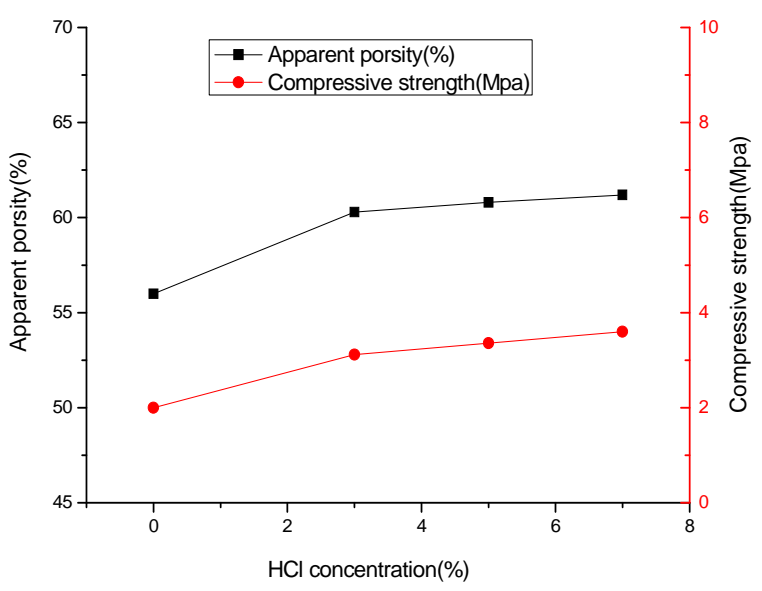

Figure 6 The effect of acid concentration on porosity and compressive strength of porous ceramics

It can be seen from Figure 6, with the increase of acid concentration on apparent porosity and compressive strength values are increased. But with the increase of acid concentration, the increase of porosity and compressive strength degree is less and less obvious. It is means that the acid concentration reaches a certain value, the impurity of coal gangue has little effect. Comprehensive consideration, the concentration of acid solution is $3 \% \mathrm{HCl}+16 \% \mathrm{H}_{2} \mathrm{SO}_{4}$ is enough.

\section{CONCLUSION}

This paper studies the process of preparing porous ceramic by adding pore forming agent. Through the experimental study, it was found that making porous agent content is $60 \%$, the sintering temperature to $1250^{\circ} \mathrm{C}$, heat-retaining time is 2 hours, the concentration of acid is $3 \% \mathrm{HCl}+16 \% \mathrm{H}_{2} \mathrm{SO}_{4}$ prepared porous ceramic with high porosity and high compressive strength. Study on the reuse of coal gangue, not only can solve the environmental problems and social problems caused by a large number of coal gangue dumps, but also to create a new economic benefits. Use of coal gangue is also in line with the country advocated the concept of circular economy, it has important significance to the environmental protection and development of industry.

\section{ACKNOWLEDGMENTS}

This paper was supported by Jiangxi social sciences planning project, Tourism landscape design research of intangible cultural heritage - in Jingdezhen ancient kiln heritage tourism landscape, for example, number: 15YS27; Presided over the Jiangxi Provincial Department of culture research project "Jingdezhen traditional culture of the construction industry in the ancient kiln landscape design research", code: YG2014177.

\section{REFERENCES}

Gong Lunlun, Cheng Xudong. A highly porous ceramics and preparation method thereof: CN104446625A [P]. 2015.

Qi Fei, Zhang Changsen. Study on Preparation of porous ceramics prepared by using coal gangue[J]. Journal of ceramics, 2015(1):58-63.

Qin Jianliang. The harm and comprehensive utilization of coal gangue[J]. Guangzhou Chemicals, 2015(4):25-27.

Wang Xianzheng. The main position of the coal energy[J]. China Coal Industry, 2014(4).

Yang Yue. Comprehensive utilization status of coal gangue in China and its bulk storage[J]. China resources comprehensive utilization, 2014(6):18-22.

Zhang Zhihao, Wang Jiao. Analysis of porous ceramic materials[J]. Shandong Industrial Technology, 2015(6):31-31. 